\title{
Increased Serum Level of CCL5 in Children with Attention-Deficit/ Hyperactivity Disorder: First Results about Serum Chemokines
}

\author{
Ahmet Özaslan', Esra Güney ${ }^{1}$, Özlem Gülbahar², Dicle Büyüktaskin ${ }^{1,3}$, Burak Arslan ${ }^{4}$ \\ Departments of ${ }^{1}$ Child and Adolescent Psychiatry, ${ }^{2}$ Medical Biochemistry, Gazi University Medical Faculty, Ankara, ${ }^{3}$ Department of Child and \\ Adolescent Psychiatry, Cizre State Hospital, Şırnak, ${ }^{4}$ Department of Medical Biochemistry, Erciş Şehit Rıdvan Çevik State Hospital, Van, Turkey
}

Objective: Attention deficit hyperactivity disorder (ADHD) is a neurodevelopmental disorder and its aetiology is not fully understood. This study aimed to determine whether the CCL5 and CCL11 influence the ADHD aetiology by comparing serum CCL5 and CCL11 levels of children with ADHD and typical development.

Methods: This study included $45(27$ males, mean age $=8.9 \pm 1.7$ years $)$ treatment-naive patients diagnosed with ADHD and 35 (20 males, mean age $=8.8 \pm 1.6$ years) healthy controls. Participants ranged in age between $6-12$ years and completed the Conners Teacher Rating Scale that assesses ADHD presentation and severity. CCL5 and CCL11 serum levels were also measured using enzyme-linked immunosorbent assay kits.

Results: Significantly higher serum CCL5 levels were found in children with ADHD compared to healthy controls $(p<$ 0.001). No significant difference was found between the mean serum CC11 level of the patients and controls $(p=$ 0.93). In addition, there was no significant correlation between the serum CCL5 and CCL11 levels and predominant presentations of ADHD and disease severity.

Conclusion: This study suggests that there are higher levels of serum CCL5 in drug naive children with ADHD, this findings suggest that CCL5 might play a role in the pathophysiology of ADHD. Moreover, these changes in peripheral blood may have therapeutic value. In addition, these results help to understand the role of chemokines in elucidating the etiopathogenesis of ADHD. Our results can be considered as the first step in investigating the role of CCL5 in $\mathrm{ADHD}$, and further research is needed to support these initial findings.

KEY WORDS: Attention deficit hyperactivity disorder; Neurodevelopmental disorders; Chemokine CCL5; Chemokines.

\section{INTRODUCTION}

Attention deficit hyperactivity disorder (ADHD) is a neurodevelopmental disorder that usually begins in childhood. The ADHD is characterized by inattention and/or hyperactivity and impulsivity symptoms that are not appropriate for the age of the person [1]. In recent epidemiological studies, the prevalence of ADHD was reported to be $5.9-7.1 \%$ [2] in the world while this rate was $12.7 \%$ in Turkey [3]. Various genetic, psychosocial, environmental, and biochemical factors are related to etiopatho-

Received: November 25, 2020 / Revised: December 26, 2020 Accepted: December 30, 2020

Address for correspondence: Ahmet Özaslan

Department of Child and Adolescent Psychiatry, Gazi University Medical Faculty, Emniyet Mahallesi Bandırma Caddesi No:6/1

Yenimahalle, Ankara 06031, Turkey

E-mail: drahmetozaslan@yahoo.com

ORCID: https://orcid.org/0000-0001-7741-201X genesis of ADHD. ADHD is a neuropsychiatric disease with a strong genetic basis [4]. There is an interaction between genetic background and environmental factors in ADHD aetiology [5]. Environmental factors may play a critical role in childhood neurodevelopmental disorders such as ADHD by triggering the activation of the immune system in the early stages of development [6]. The immune hypothesis has been proposed as a pathogenic mechanism underlying the ADHD, suggesting that changes in the immune system can lead to chronic neuroinflammation [7]. Increased levels of some inflammatory markers have been reported in children with various neuropsychiatric disorders including ADHD. This suggests that neuroinflammation may play a role in the pathogenesis of such diseases [8]. Neuroinflammation is defined as a general term of neural tissue inflammation and is characterized by changes in microglia, astrocytes, cytokines,

@) This is an Open-Access article distributed under the terms of the Creative Commons Attribution Non-Commercial License (http://creativecommons.org/licenses/by-nc/4.0) which permits unrestricted non-commercial use, distribution, and reproduction in any medium, provided the original work is properly cited. 
chemokines and related molecular processes within the central nervous system (CNS) [9]. Research evidence showed that neuroinflammation affects brain development and increases the risk of neurodevelopmental disorders through mechanisms involving glial activation, increased oxidative stress, abnormal neuronal development, low neurotrophic support, and altered neurotransmitter function $[6,9]$.

The main function of chemokines, which constitute a large family of low molecular weight cytokines, is to provide leukocyte migration to inflammatory sites. Leukocyte migration is a regular process and chemokines play roles in integrin-mediated adhesion of leukocytes rolling on endothelial cells among other effects [10]. In addition to chemotaxis, chemokines are involved in nerve development and synaptic transmission in CNS. Chemokines may cause temporary or permanent changes in brain development and function by regulating CNS in inflammatory conditions or neurogenesis [11]. Chemokines and other inflammatory mediators that affect microglia and astrocytes in physiological conditions, contribute to physiological processes such as memory, learning, brain development, and synapse formation [12]. The physiological roles of chemokines mainly cause chemotaxis, involved in CNS development and homeostatic migration, and homing and turnover of various cells, including neural precursors in the adult brain, and neuromodulation $[13,12]$. Early evidence suggests new non-immune and CNS-specific chemokine mechanisms, including neuroendocrine regulation, and direct neurotransmitter-like effects [14]. In CNS, choroid plexus epithelial cells, pericytes, astrocytes and microglia produce Eotaxin-1/CCL11 (chemokine $\mathrm{C}-\mathrm{C}$ motif ligand-11) as a result of inflammatory stimuli [15]. CCL5 (chemokine $\mathrm{C}-\mathrm{C}$ motif ligand-5) has been shown to exhibit various chemotactic functions in the inflamed CNS through its receptors of CCR5, including its effects on monocytes, microglia and neutrophils $[14,16]$.

The relationship between the CCL11 and CCL5 and many psychiatric disorders such as autism spectrum disorder (ASD), major depressive disorder, schizophrenia and bipolar disorder were investigated in previous research [17-19]. For example, in a study conducted by Vargas et al. [20], the ASD Eotaxin-1 (CCL11) was found to be high in anterior cingulate gyrus astrocytes suggesting that Eotaxin-1 increased 12 times in cerebrospinal fluid compared to the control group in children with ASD. In another study, children with ASD were found to have higher levels of MCP-1, RANTES (CCL5) and Eotaxin-1 plasma levels in comparison with the control group and those with developmental delay except ASD [21]. Also, the CCL5 plasma levels were significantly higher in patients with depression than the control group [22]. Teixeira et al. [10] investigated the serum levels of six chemokines (CCL2, CCL3, CCL11, CXCL8, CXCL9, CXCL10) in 40 schizophrenia patients and 20 control groups. Their results showed that only eotaxin-1/CCL11 serum levels were increased in patients compared to the control group. Furthermore, Barbosa et al. [23] compared the plasma IP-100/CXCL10, Eotaxin-1/CCL11, CCL2, CCL3 and CXCL8 levels of the case group consisting of 70 bipolar disorder type 1 patients (35 of them in euthymic state, 35 of them in manic phase) and the healthy control group consisting of 50 participants. The independence of the mood stage IP-100/CXCL10 and Eotaxin-1/CCL11 plasma levels have been shown to be higher in the case group than the control group.

Due to the interest in the investigation of immune biomarkers and their role in the pathophysiology of psychiatric disorders, chemokines have been investigated in many neuropsychiatric disorders such as major depression, bipolar disorder, autism, and schizophrenia $[14,15,18,19]$. Literature suggests that chemokines may be related to ADHD pathophysiology. However, this notion has not been fully tested and understood. Given that ADHD is one of the most common neurodevelopmental disorders that are associated with many neuropsychiatric diseases, it is important to investigate the role of CCL11 and CCL5 in ADHD Thus, this study, for the first time, aims to determine whether the CCL11 and CCL5 are associated with ADHD by comparing serum CCL11 and CCL5 levels of children with ADHD and typical development.

\section{METHODS}

\section{Participants}

The sample of this study consisted of 45 patients newly diagnosed with ADHD and 35 controls from the Gazi University Medical Faculty, Child and Adolescent Psychiatry Department. The patient group included children and adolescents, aged between 6 and 12 years. They applied for care in the Child and Adolescent Psychiatry Depart- 
ment and have been newly diagnosed with ADHD according to the Diagnostic and Statistical Manual of Mental Disorders 5th edition (DSM-5) criteria with no initiation of medical treatment. Control group was recruited from those who applied to the same department with different complaints such as adaptation problems to school life, sibling rivalry, and adolescence crisis. Following the detailed clinical evaluation according to DSM-5 diagnostic criteria for psychiatric disorders, children and adolescents, who had no previously known psychopathology, were included in the study. The same exclusion criteria were applied for both groups. Patients with comorbid psychiatric, neurological or genetic disorders as well as patients with chronic systemic diseases such as endocrinological and allergic disorders were not included in the study. Patients with a history of psychotropic drug use were also excluded from the study. The control group consisted of healthy children matched with the ADHD group in terms of age and sex.

\section{Procedure}

This study employed a cross-sectional design which was descriptive in nature. This study was conducted between July 2018 and March 2019. The study compared the serum CCL11 and CCL5 levels between the children diagnosed with ADHD and the control group to examine the possible relationship between the ADHD and serum CCL11 and CCL5 levels. All patients and their families were fully informed about the purpose of the study and their rights during and after the involvement in the study. They were also assured about anonymity and confidentiality of the responses. The patients who accepted to take part in the study, were asked to give their basic demographic information and the study measure described above. Then the patients who accepted to take part in the study were administered the Conners Teacher Rating Scale (CTRS) includes 28 items and each of the items is rated on a 4-point Likert scale, varying from never (0) to always (3). The scale is used to measure the subtypes and severity of ADHD. Each item on the scale is assessed and administered by teachers, whose assessments are based on observations of the behavioral aspects of students in the classroom. The adaptation of the scale into Turkish was made by Dereboy et al. [24] who found a good internal consistency statistic $(\alpha=0.95)$. In this study, $10 \mathrm{ml}$ sample of venous blood was taken from all participants.
Written informed consent was obtained from all participants. Ethical approval of the study was obtained from Gazi University Faculty of Medicine Clinical Research Ethics Committee. This study protocol has been approved by the ethics committee at Gazi University Faculty of Medicine (Number: 24074710-694.01). All procedures performed in studies involving human participants were in accordance with the ethical standards of the institutional and/or national research committee and with the 1964 Helsinki declaration and its later amendments or comparable ethical standards.

\section{Blood Samples and Determination of Serum CCL11 and CCL5 Levels}

Blood samples were collected from the ADHD patients and control groups to assess their serum CCL11 and CCL5 levels. Blood samples were taken from both groups between 8:00 - 10:00 am to prevent diurnal variation. Venous blood samples were collected from an antecubital vein; $8.5 \mathrm{ml}$ of venous blood from each patient was sampled in biochemistry tubes with silica clot activator. The tubes were centrifuged at $1,000 \times g$ for 20 minutes after an incubation period of 30 minutes at room temperature. The samples were analysed in a single session without designating whether they were from the control or patient group. Samples were stored frozen at $-80^{\circ} \mathrm{C}$ before the analysis. Serum CCL11 levels were measured using a commercially available enzyme-linked immunosorbent assay (ELISA) kit (USCN life science kit Inc., Lot: L190205416). The intra-assay and inter-assay variation coefficients were $<10 \%$ and $<12 \%$, respectively, with a limit of detection: 5,7 pg/ml. Serum CCL5 levels were measured with CCL5 ELISA kit (USCN life science kit Inc., Lot: L190408605, Wuhan, China). The intra-assay and inter-assay variation coefficients were $<10 \%$ and $<12 \%$, respectively, with a limit of detection: $0,059 \mathrm{ng} / \mathrm{ml}$. CCL11 and CCL5 levels were calculated by subjecting the optical densities of the samples to concentrations of known standards as provided in the ELISA kit and then performed a correlation analysis.

\section{Statistical Analysis}

The Kolmogorov Smirnov test was used to test the distribution of the data. Independent sample $t$ test and MannWhitney $U$ test were respectively used to analyse normally and non-normally distributed data to compare the 
groups. For example, age and CC11 levels in the ADHD and control group were compared using an independent sample $t$ test, while Mann-Whitney $U$ test was used for the comparison of CCL5. Chi-square test was used for comparing the sex of the groups. Kruskal -Wallis test was used to compare age, serum CC11 and CCL5 levels for ADHD presentation types (ADHD predominantly hyperactive/impulsive presentation, ADHD predominantly inattentive presentation and ADHD combined presentation). Spearman's correlations were used to analyse the associations between serum levels, age and CTRS scores. Statistical significance was set at $p<0.05$. All data were analysed using SPSS version 21.0 for Windows (IBM Co., Armonk, NY, USA).

\section{RESULTS}

In this study, there were $45 \mathrm{ADHD}$ patients (mean age $=$ $8.9 \pm 1.7$, age range $=6-12$ ) and 35 healthy controls (mean age $=8.8 \pm 1.6$, age range $=6-12$ ). Most of the participants were males; $60.0 \%$ (ADHD group) and $57.1 \%$

Table 1. Sociodemographic data for ADHD and control groups

\begin{tabular}{lccc}
\hline Variables & ADHD $(\mathrm{n}=45)$ & Controls $(\mathrm{n}=32)$ & $p$ value \\
\hline Sex & & & 0.80 \\
Male & $27(60)$ & $20(57.1)$ & \\
Female & $18(40)$ & $15(42.9)$ & \\
Age $(\mathrm{yr})$ & $8.9 \pm 1.7$ & $8.8 \pm 1.6$ & 0.85 \\
\hline
\end{tabular}

Values are presented as number (\%) or mean \pm standard deviation. ADHD, attention deficit hyperactivity disorder. $p<0.05$

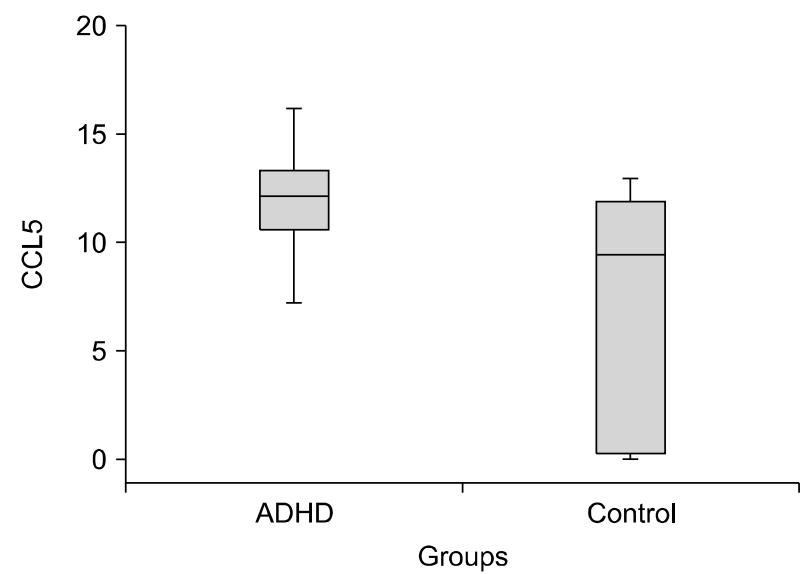

Fig. 1. Serum CCL5 levels of the ADHD and control groups. $\mathrm{ADHD}$, attention deficit hyperactivity disorder. (control group). There were no age and sex differences across the groups $\left(\mathrm{t}=0.20, p=0.85 ; \chi^{2}=0.07, p=0.80\right.$; respectively) (Table 1 ).

The presentations of the ADHD group were combined for $66.7 \%(n=30)$, predominantly inattentive for $26.7 \%$ $(\mathrm{n}=12)$ and ADHD predominantly hyperactive/ impulsive for $6.7 \%(n=3)$. Mean scores of CTRS-hyperactivity, CTRS-attention deficit, and CTRS-behavioural problem were respectively $11.86 \pm 4.08,13.08 \pm 3.80$, and $9.60 \pm 4.48$ for the ADHD patients.

There was a significant difference between the mean serum CCL5 level of the ADHD patients $(11.55 \pm 2.57$ $\mathrm{ng} / \mathrm{ml})$ and the controls $(7.35 \pm 5.11 \mathrm{ng} / \mathrm{ml}), \mathrm{Z}=-4.059$, $U=369, p<0.01$ (Fig. 1). The serum CCL5 levels of the ADHD predominantly hyperactive/impulsive presentation $(10.75 \pm 2.27 \mathrm{ng} / \mathrm{L})$, ADHD predominantly inattentive presentation $(11.18 \pm 2.68 \mathrm{ng} / \mathrm{L})$ and ADHD combined presentation $(11.78 \pm 2.60 \mathrm{ng} / \mathrm{L})$ were not statistically significantly different from each other $\left(\chi^{2}=1.206, p=\right.$ 0.55). Furthermore, there was not a significant difference between the mean serum CC11 level of the ADHD patients $(38.76 \pm 0.60 \mathrm{pg} / \mathrm{ml})$ and the controls $(38.77 \pm 0.74$ $\mathrm{pg} / \mathrm{ml}, \mathrm{t}=-0.09, p=0.93$ ) (Fig. 2).

There was no significant correlation between the serum CCL 5 and CC 11 levels $(r=-0.11, p=0.35)$. The correlations between the CC11 levels and CTRS scores were not also significant $(r=-0.22, p=0.11$ for hyperactivity; $r=$ $-0.06, p=0.69$ for attention deficit; $r=-0.20, p=0.18$ for behavioural problems). Furthermore, the Serum CCL5 levels and CTRS scores were not significantly correlated $(r=$ 0.103, $p=0.501$ for hyperactivity; $r=0.15, p=0.34$ for

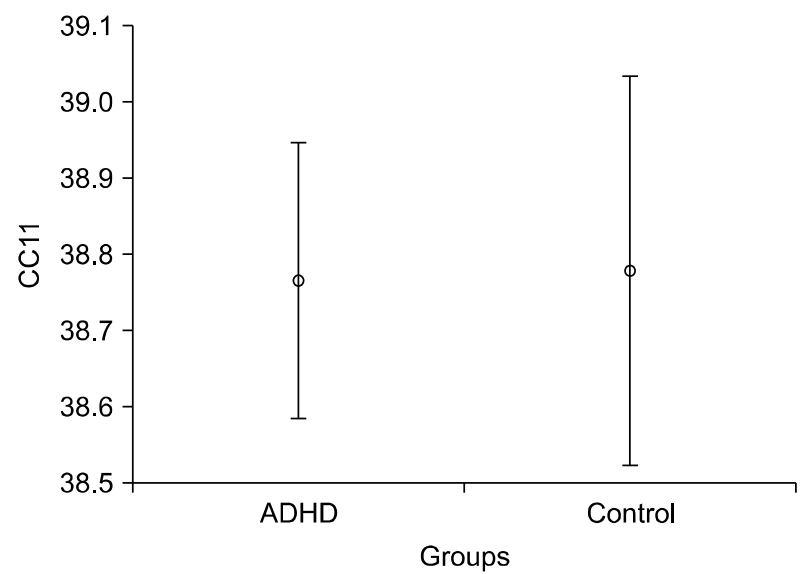

Fig. 2. Serum CC11 levels of the ADHD and control groups. ADHD, attention deficit hyperactivity disorder. 
attention deficit; $r=0.12, p=0.42$ for behavioural problems). There were no significant correlations between the age and serum CC11 levels $(r=0.03, p=0.82)$ or CCL5 levels $(r=-0.11, p=0.35)$.

\section{DISCUSSION}

The present study investigated the role of chemokines and the immune system in the pathogenesis of $\mathrm{ADHD}$ through measurement of serum CCL11 and CCL5. We compared the serum CCL11 and CCL5 levels of children and adolescents diagnosed with treatment-naïve ADHD and age and sex matched healthy controls. Serum CCL5 levels in ADHD patients were found to be significantly higher than the control group. However, there was no significant difference in serum CCL11 levels between the groups. In addition, no significant correlation was found between the predominantly presentations of ADHD and CTRS scores and serum CCL11 and CCL5 levels. To the best of our knowledge, this study is the first study to investigate the relationship between the ADHD, serum CCL11 and CCL5 levels.

In a study comparing chemokine levels of children with only ASD and with ASD + ADHD compared to healthy children with age and sex matched, CCL5 level was found to be higher in both groups compared to healthy controls [18]. In the same study, a significant correlation was found between increased levels of CCL5 and more symptoms of inattention/hyperactivity. This relationship has been shown in both ASD + ADHD group and only ASD group [18]. Studies also indicated that top-quartile concentrations of CCL5 may increase the risk of ADHD symptoms [25]. Serum levels of CCL5 have been shown to significantly increase in spontaneously hypertensive rats (animal model of ADHD) compared to age-matched Wistar Kyoto rats (control animals) [26]. Our results support the results of studies that indirectly emphasize the possible relationship between CCL5 and ADHD. We suggest several reasons for elevated CCL5 levels in ADHD.

Firstly, the increased serum CCL5 levels could be supposed that there is activation of the immune system in children with ADHD. Increasing evidence supports the role of inflammation in the pathophysiology of ADHD [9]. In the study conducted by Donfrancesco et al. [27], It was shown that serum IL-6 and IL-10 levels were significantly higher in children with ADHD compared to the control group. Recently a study conducted in Egypt (2018) has reported a higher serum level of IL-6 in ADHD children compared to children without ADHD [7]. In another study, it was reported that there is a relationship between pro-inflammatory serum cytokines and ADHD symptom severity [28]. Originally considered a T cell-specific protein, CCL5 has been found to be produced by many cell types including monocytes/macrophages, microglia and neurons. In addition to being essential in leukocyte recruitment, CCL5 appears to induce a pro-inflammatory profile in microglia [29]. Our results may suggest that higher CCL5 levels in children with ADHD may contribute to the microglial pro-inflammatory profile, which may support activation of the microglia and theoretically result in an inflammatory process leading to ADHD pathophysiology [30].

Inflammation in the brain occurs with the activation of glial cells and the production of cytokines, chemokines, and immune cell infiltration, including monocytes/macrophages, neutrophils, dendritic cells, $\mathrm{T}$ cells, and B cells [31]. CCL5 and CCL11 are important proinflammatory chemokines and produced by T cells and antigen presenting cells such as macrophages and microglia. Although it is still unclear whether T cell infiltration is primary or secondary determinant of nigrostriatal degeneration, recent studies have demonstrated a significant upregulation of CCL5 and CCL11, chemokines involved in infiltration of T cells and other immune cells, in vivo in the substantia nigra $[32,33]$. Researchers supposed that these chemokines may participate in nigrostriatal degeneration [34]. This notion is partially supported by a study in a Parkinson's disease (PD) mouse model, where it has been shown that blocking antibodies against CCL5 administered peripherally and reduced the infiltration of CD4 + and CD8 $+\mathrm{T}$ cells in the substantia nigra and prevented the loss of dopaminergic neurons [32]. Because of the essential role of an impaired dopaminergic neurotransmission in ADHD as well as in PD, mutual neurobiological underpinnings are discussed $[35,36]$. As shown in PD pathophysiology, there is increasing evidence to support the role of neuroinflammation in ADHD pathophysiology $[9,37]$. Also in children with $\mathrm{ADHD}$, nigrostriatal dopaminergic system abnormalities have been reported [38]. The results of our study can be interpreted as CCL5 may play a role in nigrostriatal abnormalities in ADHD via immune response as shown in Parkinson's disease [33]. In addition, ex- 
perimental animal studies supposed that neutralizing antibodies against CCL5 may protect nigrostriatal dopaminergic neurons [13]. For this reason, neutralization of CCL5 may be considered a new therapeutic target in ADHD.

Lastly the elevated serum levels of CCL5 may modulate dopaminergic neurotransmission in ADHD. It is widely assumed that a dysfunctional dopaminergic system leads to behavioural and cognitive deficits in ADHD, which are partially attributed to dysfunctional neural reinforcement mechanisms [39]. Abnormality in the dopaminergic system may be an indirect consequence of impaired glutamate regulation of dopamine neurons [40]. In many studies using proton magnetic resonance spectroscopy, it has been shown that glutamate levels are higher in many brain regions, including frontal, prefrontal, subcortical and striatal, in children with ADHD compared to the control group $[9,41,42]$. Then genome-wide and candidate gene association studies have shown that glutamate receptors play a role in ADHD $[43,44]$. Additionally, glutamate intake was found to be abnormal in the prefrontal cortex of the spontaneous hypertensive rat model of ADHD [45]. Besides, the chemokine system, whose role has been shown in the immune system, may participate in important physiological or pathophysiological processes in the CNS through paracrine or autocrine activities. The specific distributions of chemokines in the brain and their interactions with various neurotransmitter and neuropeptide systems support this hypothesis $[12,46,47]$. A study on mice reported that the CCL5 has been shown to modulate the release of glutamate from both the cortex and the spinal cord through interactions with CCR1 and CCR5 receptors [16]. In the light of the literature $[9,45]$ our results can be interpreted that increased CCL 5 activity may indirectly contribute to impaired dopamine neurotransmission in ADHD via glutamatergic and GABAergic systems.

A recent meta-analysis study that analyses the differences between serum cytokine and chemokine levels of individuals with autism and healthy controls found that the serum CCL11 levels of individuals with autism were significantly higher than the control group [48]. However, it is important to note that altered levels of CCL11 are associated with other psychiatric conditions such as dysthymia, obsessive compulsive disorder, and substance use disorders in children and adolescents [15]. Similar results have been reported from studies on animals. For example, higher levels of CCL2, CCL11, CCL12, and CCL19 were found to be associated with deficits in the hippocampus-related learning and memory tasks frequently seen in ADHD [49]. In our study, no difference was found between the serum CCL11 levels of the ADHD and control groups. In addition, no relationship was found between both predominantly presentations of ADHD and CTRS scores and serum CCL11 levels. Since this study is the first attempt to examine the relationship between CCL11 level and ADHD, more evidence is needed to draw a definitive conclusion. Thus, future research should replicate the present findings by using larger samples.

Chemokines have been implicated in the pathophysiology of various neuropsychiatric disorders. Despite the scarcity of evidence concerning the role of chemokines in ADHD pathophysiology, the present findings support the hypothesis that there may be a relationship between the CCL5 and ADHD pathophysiology. Nevertheless, chemokines may play a functional role in the modulation of inflammation that could affect several neurotransmitter systems which are related to the pathophysiology of neurodevelopmental disorders. For this reason, chemokines could be considered a new therapeutic target in neurodevelopmental disorders, such as ADHD and ASD. This is important in terms of providing initial evidence that forms the basis of future research and practice. In future, genetic and experimental studies are needed to investigate whether increased CCL5 levels are the cause or consequence of the disturbed process in ADHD or not. There are several merits and demerits of this study. The inclusion criterion of the sample is an important strength of our study. Our sample consists of only drug-naïve patients, who did not have any other psychiatric disorders and comorbid diseases that can be associated with peripheral chemokine level. However, there are several limitations of our study. The first limitation is that this study had a relatively small sample size of 45 patients with ADHD and 35 healthy controls. Such a small sample size restricts the capability to determine the prognostic implication of serum CCL5 and CCL11 levels. Another limitation is that there are more chemokines than CCL5 and CCL11 that may be related with neuroinflammation [12]. However, in this study, we only focused on CCL5 and CCL11. The reason is that both CCL 5 and CCL11 have important roles in immune response and nervous system homeostasis. Previous 
studies have shown that the CCL11 level is associated with various psychiatric disorders [18,15]. Furthermore, studies have shown that CCL5 may be associated with ADHD in experimental animal studies and some neuropsychiatric disorders and it has been stated that this relationship needs to be investigated $[18,26]$. Future research should examine other chemokines and their possible relations to ADHD. Besides, an examination of blood parameters only in serum samples, disregarded negative early life experiences and socioeconomic status that were likely to influence blood parameters and cross-sectional design of the study were the main limitations of this study.

In conclusion, in our study showed that serum CCL5 levels were higher in the treatment-naïve children and adolescents with ADHD compared to the control group, whereas serum CCL11 levels were not different between the two groups. In addition, this difference in ADHD and healthy controls may have therapeutic value. The findings of this study shed lights on the roles of CCL5 in ADHD aetiology, which are shown to be associated with other psychiatric diseases. In addition, these results help to understand the role of chemokines in elucidating the etiopathogenesis of ADHD. Future studies involving a larger sample size are needed to examine the causal relationship between CCL5 levels and ADHD.

\section{- Funding}

None.

\section{Acknowledgments}

We would like to thank the children and their families participating in the study on a voluntary basis.

\section{Conflicts of Interest}

No potential conflict of interest relevant to this article was reported.

\section{- Author Contributions}

Conceptualization: Ahmet Özaslan, Esra Güney. Data acquisition: Ahmet Özaslan, Dicle Büyüktaşkın. Formal analysis: Dicle Büyüktaşkın, Burak Arslan. Writing - original draft: Ahmet Özaslan. Writing - review \& editing: Esra Güney, Dicle Büyüktaşkın, Burak Arslan, Özlem Gülbahar. Supervision: Esra Güney, Özlem Gülbahar.

\section{ORCID}

Ahmet Özaslan

Esra Güney

Özlem Gülbahar

https://orcid.org/0000-0001-7741-201X https://orcid.org/0000-0002-4043-8301

Dicle Büyüktaskin https://orcid.org/0000-0003-4679-3846

Burak Arslan https://orcid.org/0000-0001-7229-3226

\section{REFERENCES}

1. American Psychiatric Association. Diagnostic and statistical manual of mental disorders: DSM-5. Arlington:American Psychiatric Pub;2013.

2. Willcutt EG. The prevalence of DSM-IV attention-deficit/hyperactivity disorder: a meta-analytic review. Neurotherapeutics 2012;9:490-499.

3. Ercan ES, Bilaç Ö, Uysal Özaslan T, Rohde LA. Is the prevalence of ADHD in Turkish elementary school children really high? Soc Psychiatry Psychiatr Epidemiol 2015;50:11451152.

4. Faraone SV, Larsson H. Genetics of attention deficit hyperactivity disorder. Mol Psychiatry 2019;24:562-575.

5. Thapar A, Cooper M, Eyre O, Langley K. What have we learnt about the causes of ADHD? I Child Psychol Psychiatry 2013; 54:3-16.

6. Ceylan MF, Uneri OS, Guney E, Ergin M, Alisik M, Goker Z, et al. Increased levels of serum neopterin in attention deficit/hyperactivity disorder (ADHD). J Neuroimmunol 2014;273:111-114.

7. Darwish AH, Elgohary TM, Nosair NA. Serum interleukin-6 level in children with attention-deficit hyperactivity disorder (ADHD). J Child Neurol 2019;34:61-67.

8. Mitchell RH, Goldstein BI. Inflammation in children and adolescents with neuropsychiatric disorders: a systematic review. J Am Acad Child Adolesc Psychiatry 2014;53:274-296.

9. Dunn GA, Nigg JT, Sullivan EL. Neuroinflammation as a risk factor for attention deficit hyperactivity disorder. Pharmacol Biochem Behav 2019;182:22-34.

10. Teixeira AL, Reis HJ, Nicolato R, Brito-Melo G, Correa H, Teixeira MM, et al. Increased serum levels of CCL11/eotaxin in schizophrenia. Prog Neuropsychopharmacol Biol Psychiatry 2008;32:710-714.

11. Rostène W, Dansereau MA, Godefroy D, Van Steenwinckel J, Reaux-Le Goazigo A, Mélik-Parsadaniantz S, et al. Neurochemokines: a menage a trois providing new insights on the functions of chemokines in the central nervous system. J Neurochem 2011;118:680-694.

12. Le Thuc O, Blondeau N, Nahon JL, Rovère C. The complex contribution of chemokines to neuroinflammation: switching from beneficial to detrimental effects. Ann $N Y$ Acad $S_{C i}$ 2015;1351:127-140.

13. Bajetto A, Bonavia R, Barbero S, Florio T, Schettini G. Chemokines and their receptors in the central nervous system. Front Neuroendocrinol 2001;22:147-184. 
14. Stuart MJ, Singhal G, Baune BT. Systematic review of the neurobiological relevance of chemokines to psychiatric disorders. Front Cell Neurosci 2015;9:357.

15. Teixeira AL, Gama CS, Rocha NP, Teixeira MM. Revisiting the role of eotaxin-1/CCL11 in psychiatric disorders. Front Psychiatry 2018;9:241.

16. Di Prisco S, Summa M, Chellakudam V, Rossi PI, Pittaluga A. RANTES-mediated control of excitatory amino acid release in mouse spinal cord. I Neurochem 2012;121:428-437.

17. Simon NM, McNamara K, Chow CW, Maser RS, Papakostas $\mathrm{Gl}$, Pollack MH, et al. A detailed examination of cytokine abnormalities in Major Depressive Disorder. Eur Neuropsychopharmacol 2008;18:230-233.

18. Han YM, Cheung WK, Wong CK, Sze SL, Cheng TW, Yeung MK, et al. Distinct cytokine and chemokine profiles in autism spectrum disorders. Front Immunol 2017:8:11.

19. Sayana P, Colpo GD, Simões LR, Giridharan VV, Teixeira AL, Quevedo J, et al. A systematic review of evidence for the role of inflammatory biomarkers in bipolar patients. J Psychiatr Res 2017:92:160-182.

20. Vargas DL, Nascimbene C, Krishnan C, Zimmerman AW, Pardo CA. Neurog/ial activation and neuroinflammation in the brain of patients with autism. Ann Neurol 2005;57:67-81.

21. Ashwood P, Krakowiak P, Hertz-Picciotto I, Hansen R, Pessah $\mathrm{I}$, Van de Water J. Elevated plasma cytokines in autism spectrum disorders provide evidence of immune dysfunction and are associated with impaired behavioral outcome. Brain Behav Immun 2011;25:40-45.

22. Ogłodek EA, Szota A, Just MJ, Moś D, Araszkiewicz A. Comparison of chemokines (CCL-5 and SDF-1), chemokine receptors (CCR-5 and CXCR-4) and IL-6 levels in patients with different severities of depression. Pharmacol Rep 2014;66: 920-926.

23. Barbosa IG, Rocha NP, Bauer ME, de Miranda AS, Huguet RB, Reis HJ, et al. Chemokines in bipolar disorder: trait or state? Eur Arch Psychiatry Clin Neurosci 2013;263:159-165.

24. Dereboy C, Senol S, Sener S, Dereboy F. IValidation of the Turkish versions of the short-form Conners' teacher and parent rating scales]. Turk Psikiyatri Derg 2007;18:48-58. Turkish.

25. Allred EN, Dammann O, Fichorova RN, Hooper SR, Hunter SJ, Joseph RM, et al. Systemic inflammation during the first postnatal month and the risk of attention deficit hyperactivity disorder characteristics among 10 year-old children born extremely preterm. J Neuroimmune Pharmacol 2017;12:531-543.

26. Kozłowska A, Wojtacha P, Równiak M, Kolenkiewicz $M$, Huang ACW. ADHD pathogenesis in the immune, endocrine and nervous systems of juvenile and maturating SHR and WKY rats. Psychopharmacology (Berl) 2019;236:2937-2958.

27. Donfrancesco R, Nativio P, Borrelli E, Giua E, Andriola E, Villa $\mathrm{MP}$, et al. Serum cytokines in paediatric neuropsychiatric syndromes: focus on Attention Deficit Hyperactivity Disorder. Minerva Pediatr 2016. [Epub ahead of print]

28. Oades RD, Dauvermann MR, Schimmelmann BG, Schwarz
MJ, Myint AM. Attention-deficit hyperactivity disorder $(A D H D)$ and glial integrity: S10OB, cytokines and kynurenine metabolism--effects of medication. Behav Brain Funct 2010; 6:29.

29. Skuljec J, Sun H, Pul R, Bénardais K, Ragancokova D, Moharregh-Khiabani $\mathrm{D}$, et al. CCL5 induces a pro-inflammatory profile in microglia in vitro. Cell Immunol 2011;270: 164-171.

30. Anand D, Colpo GD, Zeni G, Zeni CP, Teixeira AL. Attentiondeficit/hyperactivity disorder and inflammation: what does current knowledge tell us? A systematic review. Front Psychiatry 2017;8:228.

31. Alvarez-Arellano L, González-García N, Salazar-García M, Corona JC. Antioxidants as a potential target against inflammation and oxidative stress in attention-deficit/hyperactivity disorder. Antioxidants (Basel) 2020;9:176.

32. Chandra G, Rangasamy SB, Roy A, Kordower JH, Pahan K. Neutralization of RANTES and eotaxin prevents the loss of dopaminergic neurons in a mouse model of Parkinson disease. J Biol Chem 2016;291:15267-15281.

33. Dutta D, Kundu M, Mondal S, Roy A, Ruehl S, Hall DA, et al. RANTES-induced invasion of Th17 cells into substantia nigra potentiates dopaminergic cell loss in MPTP mouse model of Parkinson's disease. Neurobiol Dis 2019;132:104575.

34. Roy A, Mondal S, Kordower JH, Pahan K. Attenuation of microglial RANTES by NEMO-binding domain peptide inhibits the infiltration of $C D 8^{+} T$ cells in the nigra of hemiparkinsonian monkey. Neuroscience 2015;302:36-46.

35. Mehler-Wex C, Riederer P, Gerlach M. Dopaminergic dysbalance in distinct basal ganglia neurocircuits: implications for the pathophysiology of Parkinson's disease, schizophrenia and attention deficit hyperactivity disorder. Neurotox Res 2006; 10:167-179.

36. Kehagia AA, Housden CR, Regenthal R, Barker RA, Müller U, Rowe J, et al. Targeting impulsivity in Parkinson's disease using atomoxetine. Brain 2014;137(Pt 7):1986-1997.

37. Hirsch EC, Hunot S. Neuroinflammation in Parkinson's disease: a target for neuroprotection? Lancet Neurol 2009;8: 382-397.

38. Romanos M, Weise D, Schliesser M, Schecklmann M, Löffler J, Warnke A, et al. Structural abnormality of the substantia nigra in children with attention-deficit hyperactivity disorder. J Psychiatry Neurosci 2010;35:55-58.

39. Warton FL, Howells FM, Russell VA. Increased glutamatestimulated release of dopamine in substantia nigra of a rat model for attention-deficit/hyperactivity disorder--lack of effect of methylphenidate. Metab Brain Dis 2009;24:599-613.

40. Volkow ND, Wang GJ, Newcorn J, Fowler JS, Telang F, Solanto MV, et al. Brain dopamine transporter levels in treatment and drug naïve adults with ADHD. Neuroimage 2007; 34:1182-1190.

41. MacMaster FP, Carrey N, Sparkes S, Kusumakar V. Proton spectroscopy in medication-free pediatric attention-deficit/ 
hyperactivity disorder. Biol Psychiatry 2003;53:184-187.

42. Bollmann S, Ghisleni C, Poil SS, Martin E, Ball J, Eich-Höchli $\mathrm{D}$, et al. Developmental changes in gamma-aminobutyric acid levels in attention-deficit/hyperactivity disorder. Trans/ Psychiatry 2015;5:e589.

43. Lasky-Su J, Neale BM, Franke B, Anney RJ, Zhou K, Maller JB, et al. Genome-wide association scan of quantitative traits for attention deficit hyperactivity disorder identifies novel associations and confirms candidate gene associations. Am J Med Genet B Neuropsychiatr Genet 2008;147B:1345-1354.

44. Huang X, Wang M, Zhang Q, Chen X, Wu J. The role of g/utamate receptors in attention-deficit/hyperactivity disorder: from physiology to disease. Am J Med Genet B Neuropsychiatr Genet 2019;180:272-286.

45. Miller EM, Pomerleau F, Huettl P, Gerhardt GA, Glaser PE. Aberrant g/utamate signaling in the prefrontal cortex and striatum of the spontaneously hypertensive rat model of attention-deficithyperactivity disorder. Psychopharmacology (Berl)
2014;231:3019-3029.

46. Banisadr G, Quéraud-Lesaux F, Boutterin MC, Pélaprat D, Zalc B, Rostène W, et al. Distribution, cellular localization and functional role of CCR2 chemokine receptors in adult rat brain. J Neurochem 2002;81:257-269.

47. van der Meer $\mathrm{P}$, Ulrich AM, Gonźalez-Scarano F, Lavi E. Immunohistochemical analysis of CCR2, CCR3, CCR5, and CXCR4 in the human brain: potential mechanisms for HIV dementia. Exp Mol Pathol 2000;69:192-201.

48. Masi A, Quintana DS, Glozier N, Lloyd AR, Hickie IB, Guastella AJ. Cytokine aberrations in autism spectrum disorder: a systematic review and meta-analysis. Mol Psychiatry 2015;20:440-446.

49. Medin T, Rinholm JE, Owe SG, Sagvolden T, Gjedde A, Storm-Mathisen J, et al. Low dopamine D5 receptor density in hippocampus in an animal model of attention-deficit/hyperactivity disorder (ADHD). Neuroscience 2013;242:11-20. 